\title{
Desempenho de híbridos de milho na Região Sudoeste do Paraná sob diferentes espaçamentos entre linhas ${ }^{1}$
}

\author{
Performance of corn hybrids at the Southwest of Paraná under different row spacing
}

\author{
Alcir José Modolo ${ }^{2 *}$, Ricardo Carnieletto ${ }^{3}$, Evandro Marcos Kolling ${ }^{4}$, Emerson Trogello ${ }^{5}$ Maicon Sgarbossa ${ }^{3}$
}

\begin{abstract}
Resumo - A manipulação do arranjo de plantas de milho, através de alterações na densidade de plantas, de espaçamento entre linhas, de distribuição de plantas na linha e na variabilidade entre plantas, é uma das práticas de manejo mais importantes para maximizar a interceptação da radiação solar, otimizar o seu uso e potencializar o rendimento de grãos. Dessa forma, objetivouse com este trabalho estudar os efeitos da combinação entre diferentes híbridos de milho e espaçamentos entre linhas no desenvolvimento da cultura em sistema de plantio direto na Região Sudoeste do Paraná. O experimento foi realizado na Área Experimental do Curso de Agronomia da UTFPR, no município de Pato Branco - Pr, com delineamento estatístico aleatorizado em blocos em esquema fatorial $(3 \times 3)$, com quatro repetições. Os tratamentos foram compostos pela combinação entre três híbridos (DKB 240, PIONEER 30R50 e SG 6010) e três espaçamentos entre linhas (0,45; 0,70 e 0,90 m). Após a semeadura, foram avaliados: a altura de plantas, o diâmetro do colmo, o rendimento de grãos e seus componentes. Os resultados mostraram que em nenhuma das avaliações houve interações entre híbridos e espaçamentos e que a redução no espaçamento entre linhas promoveu aumento no número de espigas por planta e o incremento na produtividade de grãos na cultura do milho.
\end{abstract}

Palavras-chave - Milho hibrido. Plantio direto. Componentes de rendimento.

\begin{abstract}
Corn plant arrangement is one of the most important management tool to improve solar radiation interception and it can be done through changes in plant density, row spacing, distribution of plants in the row and plant variability aiming to optimize its use and maximize the yield. Due to it, the objective of this work was to study the effects of different corn hybrids and row spacing over the corn development cultivated in a no-tillage system in the Southwest of Paraná. The experiment was carried out at the experimental area of the UTFPR Agronomy Course located in Pato Branco - Pr, following a complete randomized block design factorial $(3 \times 3)$, with four replications. The treatments consisted of combinations among three hybrids (DKB 240, Pioneer 30R50 and SG 6010) and three row spacing ( $0.45 ; 0.70$ and $0.90 \mathrm{~m}$ ). After seeding, were evaluated: plant height, stem diameter, grain yield and its components. According to the results, there were no interaction among hybrids and row spacing, the row spacing reduction promoted greater number of spikes per plant and increased corn grain yield.
\end{abstract}

Key words - Hybrid maize. No-tillage. Yield components.

\footnotetext{
* Autor para correspondência

${ }^{1}$ Recebido para publicação em 17/11/2009; aprovado em 12/07/2010

Pesquisa acadêmica desenvolvida no Curso de Agronomia da UTFPR, Campus Pato Branco-PR

${ }^{2}$ Curso de Agronomia, Universidade Tecnológica Federal do Paraná/UTFPR, Via do Conhecimento, Km 01, Pato Branco-PR, Brasil, 85.503-390, alcir@utfpr.edu.br

${ }^{3}$ Graduandos do Curso de Agronomia, Universidade Tecnológica Federal do Paraná/UTFPR, Pato Branco-PR, Brasil, rcamieletto@gmail.com, maiconssarbossa@htomail.com

${ }^{4}$ Curso de Engenharia Civil, Universidade Tecnológica Federal do Paraná/UTFPR, Pato Branco-PR, Brasil, kolling@utfpr.edu.br

${ }^{5}$ Programa de Pós-Graduação em Agronomia/UTFPR, Pato Branco-PR, Brasil, etrogello@yahoo.com.br
} 


\section{Introdução}

Entre as práticas e técnicas empregadas para a obtenção de maior produtividade de milho, a escolha do arranjo espacial de plantas na área é uma das mais importantes (ALMEIDA et al., 2000). Recentemente, os diferentes arranjos espaciais, resultantes da combinação do espaçamento entre linhas de semeadura e o número de plantas por metro, têm sido discutidos com maior freqüência pela maior ou menor adaptação da cultura ao ambiente decorrente das variações morfológicas e genéticas apresentadas pelos híbridos atuais, como forma de maximizar a produtividade de grãos pela otimização do uso de fatores de produção como água, luz e nutrientes, disponíveis em um determinado agrossistema.

Com o surgimento de novos genótipos e técnicas de manejo para a cultura de milho, numerosos estudos têm sido realizados para a determinação do melhor espaçamento e densidade de semeadura. Os resultados encontrados variam em função da região, do tipo e fertilidade do solo, disponibilidade hídrica, luminosidade, genótipos e níveis de adubação adotados (PENARIOL et al., 2003).

Pesquisas recentes têm demonstrado que a redução de espaçamento entre linhas tem contribuído para o aumento da produtividade (BALBINOT JUNIOR; FLECK, 2004; STRIEDER, 2006). Além disso, Vazquez e Silva (2002) relataram que o uso de espaçamentos menores facilita as operações mecanizadas, já que elimina o ajuste de implementos como a semeadora e o cultivador-adubador em áreas de rotação com soja ou feijão (Phaseolus vulgaris).

De acordo com Marchão et al. (2005) a introdução de híbridos com alto potencial produtivo, o incremento na utilização de fertilizantes, o desenvolvimento de novos herbicidas, a adoção do sistema de plantio direto, além de outros fatores, têm permitido a utilização de lavouras mais adensadas, que tem como principal objetivo potencializar o rendimento de grãos.

Argenta et al. (2001) ao analisarem dois híbridos simples de milho semeados em quatro espaçamentos entre linhas $(0,40 ; 0,60 ; 0,80$ e $1,00 \mathrm{~m})$ e duas populações $(50.000 \mathrm{e}$ 60.000 plantas ha $\left.\mathrm{a}^{-1}\right)$, concluíram que o rendimento de grãos é influenciado pela redução do espaçamento entre linhas e pela densidade de plantas. O aumento do rendimento de grãos é decorrente de uma melhor distribuição de plantas com redução do espaçamento entre linhas, verificado principalmente em milhos de ciclos super precoce e de estatura baixa.

Guareschi et al. (2008) ao avaliarem o potencial de produção de massa fresca e seca da cultura do milho para fins de ensilagem, verificaram que a redução do espaçamento entre linhas de 0,9 para $0,45 \mathrm{~m}$ influenciou positivamente a produção de silagem.
Em virtude das modificações introduzidas nos genótipos de milho mais recentes, tais como menor estatura de planta e altura de inserção de espiga, menor esterilidade de plantas, menor duração do subperíodo pendoamentoespigamento, plantas com folhas de angulação mais ereta e elevado potencial produtivo, torna-se necessário reavaliar as recomendações de práticas de manejo para esta cultura. Com base no exposto, objetivou-se neste trabalho estudar os efeitos da combinação entre diferentes híbridos de milho e espaçamentos entre linhas na produtividade da cultura em sistema de plantio direto na Região Sudoeste do Paraná.

\section{Material e métodos}

O experimento foi desenvolvido na área experimental da Universidade Tecnológica Federal do Paraná - UTFPR, em Pato Branco - PR, em Latossolo Vermelho aluminoférrico com textura argilosa (77,40\% de argila, $20,31 \%$ de areia e 2,29\% de silte), com $\mathrm{pH}=5,2$ e altos teores de matéria orgânica, fósforo e potássio $\left(\mathrm{MO}=53,61 \mathrm{~g} \mathrm{dm}^{-3}, \mathrm{P}=15,15 \mathrm{mg} \mathrm{dm}^{-3}\right.$, $\left.\mathrm{K}=0,35 \mathrm{cmol}_{\mathrm{c}} \mathrm{dm}^{-3}\right)$. O clima é subtropical úmido do tipo (Cfa), conforme classificação de Köppen, e precipitação pluvial média anual de $1.800 \mathrm{~mm}$ (IAPAR, 1994). A localização geográfica da área experimental está definida pelas coordenadas $26^{\circ} 16^{\prime} 36^{\prime \prime}$ de Latitude Sul e 52॰41'20" de Longitude Oeste, com uma altitude média de $760 \mathrm{~m}$ e declividade entre 0 e $3 \%$.

Utilizou-se o delineamento estatístico aleatorizado em blocos em esquema fatorial (3 x 3), com quatro repetições. A área foi dividida em quatro blocos, totalizando trinta e seis parcelas experimentais, cada uma com área de $81,4 \mathrm{~m}^{2}(3,7$ x $22 \mathrm{~m})$ e área útil de $50,4 \mathrm{~m}^{2}$ e com 10,0 metros de espaçamento entre blocos, utilizados para manobra e estabilização do conjunto motomecanizado. Os nove tratamentos foram compostos pela combinação entre três híbridos (DKB240, Pioneer 30R50 e SG 6010) e três espaçamentos entre linhas de semeadura $(0,45 ; 0,70$ e $0,90 \mathrm{~m})$.

A escolha dos híbridos se deu em função de suas características. Foram utilizados os híbridos DKB240 (híbrido simples, ciclo precoce e arquitetura foliar semiereta), Pioneer 30R50 (híbrido simples, ciclo médio, arquitetura foliar semi-ereta) e SG 6010 (híbrido simples, ciclo precoce, arquitetura foliar semi-ereta).

A adubação no momento da semeadura constituiu-se de $400 \mathrm{~kg} \mathrm{ha}^{-1}$ da formulação 08-20-20, e aos 48 dias após o plantio efetuou-se uma única aplicação de $120 \mathrm{~kg}$ de N, na forma de uréia.

O controle da lagarta do Cartucho (Spodoptera frugiperda) foi realizado aos sete e aos 50 dias após o plantio 
com a utilização do inseticida Permetrina, na dosagem de $0,1 \mathrm{~L} \mathrm{ha}^{-1}$ mais o inseticida Triflumuron, na dosagem de $0,05 \mathrm{~L} \mathrm{ha}^{-1}$, com volume de aplicação de $200 \mathrm{~L} \mathrm{ha}^{-1}$. Como adjuvante, utilizou-se óleo mineral na dosagem de $0,8 \mathrm{~L} \mathrm{ha}^{-1}$. As plantas daninhas foram controladas com herbicida Atrazina + Simazina, sete dias após a semeadura do milho, na dose de $6,0 \mathrm{~L} \mathrm{ha}^{-1}$, conforme recomendação para as ervas daninhas encontradas.

Para a semeadura do milho, utilizou-se um trator New Holland, modelo TL75E, 4 x 2 TDA (Tração Dianteira Auxiliar), com potência máxima de $57,4 \mathrm{~kW}(78 \mathrm{cv})$ no motor a $2.400 \mathrm{rpm}$ e uma semeadora-adubadora de precisão marca Vence Tudo, modelo SA 14600 de arrasto, com mecanismos sulcadores do tipo haste sulcadora para fertilizantes e discos duplos defasados para sementes e, com mecanismos de cobertura e compactação do tipo roda compactadora de borracha, tipo convexa com $330 \mathrm{~mm}$ (13”) de diâmetro e $170 \mathrm{~mm}$ de largura.

A semeadora foi regulada para distribuir 2,7; 4,2 e 5,4 sementes por metro na linha de plantio, nos espaçamentos de 0,$45 ; 0,70$ e $0,90 \mathrm{~m}$, respectivamente, para estabelecimento da população de 60.000 plantas ha $^{-1}$.

Aos 72 dias após o plantio foram realizadas medições de altura final de plantas e de inserção da primeira espiga. Essas avaliações foram realizadas com o auxilio de uma régua graduada em centímetros, em 20 plantas por parcela. O diâmetro do colmo foi avaliado logo acima do segundo nó, com o auxílio de um paquímetro digital.

De cada parcela experimental foram coletadas 10 espigas, das quais foram contadas manualmente: o número de filleiras e número de grãos por fileiras.

A colheita das espigas de milho foi manual, com debulha realizada em trilhadora estacionária. O rendimento de grãos foi estimado por meio da extrapolação da produção colhida na área útil das parcelas para um hectare, corrigindo-se a umidade para $13 \%$.

O número de espigas por planta foi determinado pela razão entre o número de espigas colhidas e o número de plantas existentes na área útil. O peso de mil grãos foi determinado pela contagem manual de 400 grãos, pesagem e correção da umidade para $13 \%$. Por regra de três simples, extrapolou-se este peso para mil grãos.

Os dados obtidos foram tabulados e submetidos às análises de variância para avaliação dos efeitos dos fatores espaçamento e tipo de híbrido e sua interação. As médias foram comparadas pelo teste de Tukey, a 5\% de probabilidade, utilizando o programa ASSISTAT 7.5 Beta (2008) desenvolvido por Silva e Azevedo (2006).

\section{Resultados e discussão}

\author{
Altura da planta, diâmetro do colmo e altura da \\ inserção de espiga
}

$\mathrm{Na}$ Tabela 1 são apresentados os valores médios da altura de plantas, onde se observa que não foram encontradas diferenças significativas para os diferentes híbridos utilizados, e não houve interação entre híbridos e espaçamentos. No entanto, o espaçamento entre linhas de $0,90 \mathrm{~m}$ resultou em maior valor de altura de plantas.

Quando se reduziu o espaçamento entre linhas, houve redução na altura de plantas, sendo os menores valores obtidos nos espaçamentos de 0,45 e 0,70 m. Isso ocorre porque a redução do espaçamento entre linhas quando se mantém a mesma população, reduz a competição entre plantas, na linha de semeadura, por água, luz e nutrientes, em razão da melhor distribuição das plantas (ARGENTA et al., 2001; PENARIOL et al., 2003; SANGOI, 2000).

Segundo Argenta et al. (2001) a utilização de espaçamentos maiores entre linhas favorece a competição por luz, o que determina algumas modificações no desenvolvimento das plantas como: maior elongação do colmo, folhas mais compridas e finas e elevadas perdas de raízes.

Lana et al. (2009) e Silva et al. (2008) encontraram resultados semelhantes aos obtidos nesse trabalho. Entretanto, diferem dos obtidos por Alvarez et al. (2006), visando estudar o comportamento de dois híbridos de diferentes arquiteturas foliares em dois espaçamentos entre linhas $(0,70$ e $0,90 \mathrm{~m})$ e duas densidades de plantas (55.000 e 70.000 plantas ha $^{-1}$ ), em dois anos agrícolas, verificaram inexistência de alteração da altura de plantas com redução de espaçamento entre linhas de 0,90 para $0,70 \mathrm{~m}$, independente do ano de plantio e de densidade de plantas.

Para o diâmetro de colmo (TAB. 1), não se observou diferenças entre os híbridos e espaçamentos utilizados, e não houve interação entre os fatores. Os resultados encontrados corroboram com os obtidos por Demétrio et al. (2008) e Penariol et al. (2003), que observaram que a redução do espaçamento não teve influência significativa sobre o diâmetro de colmo.

Com relação a altura de inserção da primeira espiga (TAB. 1), não foram observadas diferenças significativas para os diferentes híbridos utilizados, e não houve interação entre híbridos e espaçamentos, porém, para o fator espaçamento entre linhas, verificouse que os espaçamentos de 0,70 e $0,90 \mathrm{~m}$ resultaram nos maiores valores de altura de inserção da primeira espiga. Estes tratamentos também apresentaram maior altura 
Tabela 1 - Síntese da análise de variância e do teste de médias para as variáveis altura da plantas $(\mathrm{cm})$, diâmetro do colmo (cm) e altura da inserção da primeira espiga $(\mathrm{cm})$ de três híbridos de milho submetidos a três espaçamentos

\begin{tabular}{|c|c|c|c|}
\hline Tratamento & Altura de plantas & Diâmetro do colmo & $\begin{array}{c}\text { Altura de inserção da primeira } \\
\text { espiga }\end{array}$ \\
\hline \multicolumn{4}{|l|}{ Espaçamento (E) } \\
\hline $0,45 \mathrm{~m}$ & 161,49 a & 1,87 & $79,22 \mathrm{a}$ \\
\hline $0,70 \mathrm{~m}$ & $159,02 \mathrm{a}$ & 1,89 & $87,34 \mathrm{~b}$ \\
\hline $0,90 \mathrm{~m}$ & $168,15 \mathrm{~b}$ & 1,78 & $91,23 \mathrm{~b}$ \\
\hline Média & - & 1,85 & - \\
\hline Teste $\mathrm{F}$ & $10,54 * *$ & $2,60^{\text {ns }}$ & $19,66 * *$ \\
\hline DMS & 4,24 & 0,13 & 4,84 \\
\hline \multicolumn{4}{|l|}{ Híbridos (H) } \\
\hline DKB 240 & 161,66 & 1,83 & 84,36 \\
\hline PIONEER 30R50 & 162,80 & 1,87 & 86,07 \\
\hline SG 6010 & 164,20 & 1,83 & 87,36 \\
\hline Média & 162,88 & 1,84 & 85,93 \\
\hline Teste F & $0,76^{\mathrm{ns}}$ & $0,35^{\mathrm{ns}}$ & $1,19^{\mathrm{ns}}$ \\
\hline DMS & 4,24 & 0,13 & 4,84 \\
\hline Teste F (E x H) & $1,51^{\text {ns }}$ & $0,58^{\mathrm{ns}}$ & $1,50^{\mathrm{ns}}$ \\
\hline CV (\%) & 3,09 & 7,04 & 5,57 \\
\hline
\end{tabular}

Médias seguidas por letras iguais na mesma coluna não diferem entre si pelo Teste de Tukey, a $5 \%$ de probabilidade. ${ }^{\text {ns }}$ - Não significativo. * $\mathrm{e}^{* *}$ _ Significativo a 5 e $1 \%$ de probabilidade, respectivamente pelo Teste $\mathrm{F}$

de plantas, confirmando a afirmação de Silva (2000), que plantas mais altas resultam em maiores alturas de inserção da primeira espiga.

Estes resultados corroboram com resultados encontrados por Gross et al. (2006), que ao avaliarem dois espaçamentos entre linhas $(0,45$ e $0,90 \mathrm{~m})$ e dois híbridos de milho, encontraram maior altura de inserção da primeira espiga no espaçamento de $0,90 \mathrm{~m}$.

Número de fileiras por espiga, número de grãos por fileira, número de espigas por planta, peso de mil grãos e produtividade média da cultura do milho

$\mathrm{Na}$ Tabela 2 são apresentados os valores médios do número de fileiras por espiga, onde se observa que não foram encontradas diferenças significativas para os diferentes híbridos utilizados e que não houve interação entre híbridos e espaçamentos. No entanto, o espaçamento de $0,70 \mathrm{~m}$ resultou em maior número de fileiras por espiga, quando comparado com os demais. Já, o espaçamento de $0,45 \mathrm{~m}$ foi o que apresentou menor número de fileiras por espiga, fato este que pode ter ocorrido devido ao uso de híbridos de arquitetura foliar semi-ereta, que ocasionaram aumento de competição intra-especifica por luz com a redução do espaçamento entre linhas. Este resultado contradiz Palhares (2003), que afirma que a redução do espaçamento entre linhas induz a um aumento significativo no número de fileiras por espiga.

Para o número de grãos por fileira (TAB. 2), notase que não foram encontradas diferenças significativas para os diferentes híbridos utilizados e que não houve interação entre híbridos e espaçamentos. No entanto, o espaçamento de $0,90 \mathrm{~m}$ resultou em maior número de grãos por fileiras, quando comparado com os demais. $\mathrm{O}$ espaçamento de $0,70 \mathrm{~m}$ foi o que apresentou menor número de grãos por fileira.

Observa-se na Tabela 2 que apenas o espaçamento entre linhas afetou de forma significativa o número de espigas por planta, sendo que o espaçamento de $0,45 \mathrm{~m}$ resultou em maior número de espigas quando comparado aos espaçamentos de 0,70 e $0,90 \mathrm{~m}$, respectivamente.

Penariol et al. (2003) avaliando o híbrido AG-9010 e a variedade BR473 em três espaçamentos entre linhas $(0,40 ; 0,60$ e $0,80 \mathrm{~m})$, também não verificaram influência das cultivares sobre o número de espigas por planta. 
Tabela 2 - Síntese da análise de variância e do teste de médias para as variáveis número de fileiras por espiga, número de grãos por fileira, número de espigas por planta, peso de mil grãos $(\mathrm{g})$ e produtividade $\left(\mathrm{kg} \mathrm{ha}^{-1}\right)$ de três híbridos de milho submetidos a três espaçamentos

\begin{tabular}{cccccc}
\hline Tratamento & $\begin{array}{c}\text { Número de } \\
\text { fileiras por espiga }\end{array}$ & $\begin{array}{c}\text { Número de grãos } \\
\text { por fileira }\end{array}$ & $\begin{array}{c}\text { Número de espigas } \\
\text { por planta }\end{array}$ & Peso de mil grãos & Produtividade \\
\hline Espaçamento (E) & & & & & \\
$0,45 \mathrm{~m}$ & $13,57 \mathrm{~b}$ & $35,58 \mathrm{ab}$ & $1,06 \mathrm{a}$ & 332,89 & $7624,63 \mathrm{a}$ \\
$0,70 \mathrm{~m}$ & $14,48 \mathrm{a}$ & $34,54 \mathrm{~b}$ & $1,00 \mathrm{~b}$ & 319,76 & $7743,89 \mathrm{a}$ \\
$0,90 \mathrm{~m}$ & $14,07 \mathrm{ab}$ & $36,74 \mathrm{a}$ & $1,00 \mathrm{~b}$ & 332,87 & $6672,83 \mathrm{~b}$ \\
\hline Média & - & - & 1,02 & 328,06 & - \\
\hline Teste F & $7,69^{* *}$ & $4,07^{*}$ & $27,42^{* *}$ & $1,36^{\text {ns }}$ & $6,77^{* *}$ \\
DMS & 0,58 & 1,91 & 0,02 & 22,70 & 789,98 \\
Híbridos (H) & & & & $310,34 \mathrm{a}$ & 7430,63 \\
DKB 240 & 14,03 & 36,12 & 1,02 & $359,29 \mathrm{~b}$ & 7597,92 \\
PIONEER 30R50 & 13,93 & 35,60 & 1,02 & $315,89 \mathrm{a}$ & 7012,98 \\
\hline SG 6010 & 14,15 & 35,14 & 1,03 & - & 7347,17 \\
\hline Média & 14,03 & 35,62 & 1,02 & $17,09 * *$ & $1,78^{\text {ns }}$ \\
\hline Teste F & $0,43^{\text {ns }}$ & $0,80^{\text {ns }}$ & $0,47^{\text {ns }}$ & 22,70 & 789,98 \\
\hline DMS & 0,58 & 1,91 & 0,02 & $0,19^{\text {ns }}$ & $0,37^{\text {ns }}$ \\
\hline Teste F (E x H) & $0,50^{\text {ns }}$ & $0,94^{\text {ns }}$ & $0,68^{\text {ns }}$ & 6,84 & 10,63 \\
\hline CV (\%) & 4,08 & 5,31 & 2,27 & & \\
\hline
\end{tabular}

Médias seguidas por letras iguais na mesma coluna não diferem entre si pelo Teste de Tukey, a $5 \%$ de probabilidade. ${ }^{\text {ns }}$ - Não significativo. ${ }^{*} \mathrm{e}^{* *}$ Significativo a 5 e $1 \%$ de probabilidade, respectivamente pelo Teste $\mathrm{F}$

Para o peso de mil grãos pode-se observar que de todos os fatores e interações estudados, apenas os híbridos apresentaram diferenças significativas, sendo que o híbrido Pioneer 30R50 resultou em maior peso de mil grãos quando comparado com os demais. No entanto, o aumento do peso de mil grãos para o híbrido Pioneer 30R50 não refletiu o mesmo aumento na produtividade (TAB. 2).

Resultados semelhantes foram obtidos por Amaral Filho (2005), Argenta et al. (2001), Dallastra et al. (2009), Demétrio et al. (2008), Balbinot Júnior e Fleck (2004) e Flesch e Vieira (2004), os quais não encontraram diferenças significativas para o peso de mil grãos nos diferentes espaçamentos utilizados. Silva et al. (2009), em trabalho realizado com o objetivo de identificar o arranjo ideal de plantas por unidade de área, utilizando híbridos comerciais, cultivados sob diferentes densidades populacionais com base no espaçamento entre linhas e de plantas por metro linear, observaram que as diferenças proporcionadas nos componentes de rendimento de milho, entre elas o peso de mil grãos, se devem mais a densidade populacional do que exclusivamente ao espaçamento entre linhas.
Nota-se, na Tabela 2 que apenas o espaçamento entre linhas afetou de forma significativa a produtividade de grãos, sendo que o espaçamento de $0,90 \mathrm{~m}$ resultou em menor produtividade de grãos quando comparado aos espaçamentos de 0,70 e $0,45 \mathrm{~m}$.

Os estudos de redução do espaçamento entre linhas sobre o rendimento de grãos de milho apresentam resultados bastante heterogêneos. Enquanto, alguns resultados indicam aumentos expressivos de rendimento de grãos com a redução do espaçamento entre linhas (BALBINOT JÚNIOR; FLECK, 2004; JOHNSON; HOVERSTAD, 2002; SHRESTHA et al., 2001; STRIEDER, 2006), outros, não detectaram qualquer benefício da utilização de linhas mais próximas sobre o rendimento de grãos de milho (FLESCH; VIERA, 2004; PITOMBEIRA; NUNES, 1995; TREZZI et al., 2008). Esses resultados existentes na literatura podem ser atribuídos a diversos fatores, entre os quais se pode citar o tipo de híbrido, população de plantas, as características climáticas da região e o nível de fertilidade do solo, dentre outros (SANGOI et al., 2002).

Os resultados obtidos na avaliação da produtividade corroboram com resultados encontrados por Gross et al. 
(2006), que ao avaliarem dois espaçamentos entre plantas $(0,45$ e $0,90 \mathrm{~m})$ e dois híbridos de milho, constataram que o espaçamento de $0,45 \mathrm{~m}$ proporcionou maior produtividade de grãos que o espaçamento de $0,90 \mathrm{~m}$.

Segundo Argenta et al. (2001), o aumento da produtividade de grãos, com a redução do espaçamento entre linhas, é atribuído à maior eficiência na interceptação de radiação e ao decréscimo de competição por luz, água e nutrientes, entre as plantas na linha, devido a sua distribuição mais eqüidistante.

O fato dos híbridos não terem apresentado diferenças significativas entre si sobre a produtividade de grãos, pode estar relacionado ao fato de todos os híbridos utilizados possuírem arquitetura foliar semi-ereta. Dourado Neto et al. (2003) também não verificaram diferenças em produtividade de grãos na redução de espaçamentos de 0,80 para $0,40 \mathrm{~m}$ em nenhuma das populações avaliadas para híbridos de arquitetura foliar semi-ereta.

\section{Conclusões}

1. A redução no espaçamento entre linhas de $0,90 \mathrm{~m}$ para 0,45 m promoveu aumento do número de espigas por planta e o incremento na produtividade de grãos na cultura do milho;

2. A redução do espaçamento entre linhas reduziu a altura de plantas e de inserção da primeira espiga;

3. O híbrido PIONEER 30R50 apresentou maior peso de mil grãos, no entanto, isso não acarretou em aumento de produtividade, quando comparado com os híbridos DKB 240 e SG 6010.

\section{Agradecimentos}

Os autores agradecem a Fundação Araucária pela bolsa de iniciação científica do segundo autor e as empresas Sementes Guerra S.A. e Nativa Produtos Agrícolas Ltda. pelo apoio.

\section{Referências}

ALMEIDA, M. L.; SANGOI, L.; ENDER, M. Incremento na densidade de plantas: uma alternativa para aumentar o rendimento de grãos de milho em regiões de curta estação estival de crescimento. Ciência Rural, v. 30, n. 01, p. 23-29, 2000.

ALVAREZ, C. G. D.; VON PINHO, R. G.; BORGES, I. D. Avaliação de características agronômicas e de produção de forragem e grãos de milho em diferentes densidades de milho e espaçamento entre linha. Ciência e Agrotecnologia, v. 30, n. 03, p. 402-408, 2006.

AMARAL FILHO, J. P. R. do. et al. Espaçamento, densidade populacional e adubação nitrogenada na cultura do milho. Revista Brasileira de Ciência do Solo, v. 29, n. 03, p. 467-473, 2005.

ARGENTA, G. S. et al. Resposta de híbridos simples à redução do espaçamento entre linhas. Pesquisa Agropecuária Brasileira, v. 36, n. 01, p. 71-78, 2001.

BALBINOT JUNIOR.; FLECK, N. G. Manejo de plantas daninhas na cultura de milho em função do arranjo espacial de plantas e características dos genótipos. Ciência Rural, v. 34, n. 06 , p. $245-252,2004$

DALLASTRA, A. et al. Produtividade de variedades de milho sobre influência do espaçamento entre linhas e densidade populacional. Cultivando o saber, v. 02, n. 02, p. 128-136, 2009.

DEMÉTRIO, C. S. et al. Desempenho de híbridos de milho submetidos a diferentes espaçamentos e densidades populacionais. Pesquisa Agropecuária Brasileira, v. 43, n. 12, p. 1691-1697, 2008.

DOURADO NETO, D. et al. População e distribuição espacial de plantas de milho. In: FANCELLI, A. L.; DOURADO NETO, D. Milho: estratégias de manejo para alta produtividade. São Paulo: ESALQ/USP/LPV, 2003. p. 116-133.

FLESCH, R. D.; VIEIRA, L. C. Espaçamento e densidade de milho com diferentes ciclos no oeste de Santa Catarina. Ciência Rural, v. 34, n. 01, p. 25-31, 2004.

GROSS, M. R.; PINHO, R. G. V.; BRITO, A. H. de. Adubação nitrogenada, densidade de semeadura e espaçamento de fileiras na cultura do milho em sistema plantio direto. Ciência e Agrotecnologia, v. 30, n. 03, p. 387-393, 2006.

GUARESCHI, R. F. et al. Produção de milho silagem em função do arranjo populacional e adubação. Revista Ciência Agronômica, v. 39, n. 03, p. 468-475, 2008.

INSTITUTO AGRONÔMICO DO PARANÁ (IAPAR). Cartas climáticas do estado do Paraná 1994. Londrina: IAPAR, 1994. 49 p.

JOHNSON, G. A.; HOVERSTAD, T. R. Effect of row spacing and herbicide application timing on weed control and grain yield in corn (Zea mays). Weed Technology, v. 16, n. 03, p. 548-553, 2002.

LANA, M. C. et al. Arranjo espacial e adubação nitrogenada em cobertura na cultura do milho. Acta Scientiarum. Agronomy, v. 31, n. 03, p. 433-438, 2009.

MARCHÃO, R. L. et al. Densidade de plantas e características agronômicas de híbridos de milho sob espaçamento reduzido entre linhas. Pesquisa Agropecuária Tropical, v. 35, n. 02, p. 93-101, 2005.

PALHARES, M. Distribuição e população de plantas e produtividade de grãos de milho. 2003. 90 f. Dissertação (Mestrado em Agronomia/Fitotecnia) - Universidade de São Paulo, Piracicaba. 
PENARIOL, F. G. et al. Comportamento de cultivares de milho semeados em diferentes espaçamentos entre linha e densidades populacionais, na safrinha. Revista Brasileira Milho e Sorgo, v. 02, n. 02 , p. $52-60,2003$.

PITOMBEIRA, J. B.; NUNES, R. de P. Produção de milho sequeiro em função da fertilização, densidade de plantio e espaçamento. Revista Ciência Agronômica, v. 26, n. 01/02, p. 39-44, 1995.

SANGOI, L. et al. Sustentabilidade do colmo em híbridos de milho de diferentes épocas de cultivo em função da densidade de plantas. Revista de Ciências Agroveterinárias, v. 01, n. 02, p. 63-72, 2002.

SANGOI, L. Understending plant density effects on maize grouth and development: en important issue to maximize groin yeld. Ciência Rural, v. 31, n. 01, p. 159-168, 2000.

SHRESTA, A. et al. An integrated weed management strategy for glufosinate-resistant corn (Zea mays). Weed Technology, v. 15, n. 04, p. $517-522,2001$.

SILVA, A. R. B. Comportamento de variedades/híbridos de milho (Zea mays L.) em diferentes tipos de preparo do solo. 2000. 96 f. Dissertação (Mestrado em Energia na Agricultura) - Universidade Estadual Paulista, Botucatu.

SILVA, F. de A. S. E.; AZEVEDO, C. A. V. de. A New Version of The Assistat-Statistical Assistance software. In: WORLD
CONGRESS ON COMPUTERS IN AGRICULTURE, 4., 2006, Orlando-FL-USA: Anais... Orlando: American Society of Agricultural Engineers, 2006. p. 393-396.

SILVA, A. G. da et al. Influencia da população de plantas e do espaçamento entre linhas nos caracteres agronômicos do hibrido de milho P30K75 em Rio Verde, Goiás. Bioscience jornal, v. 24, n. 02, p. 89-96, 2008.

SILVA, A. J. da et al. Arranjo populacional em híbridos de milho na expressão de compomentes diretos de produção. In: CONGRESSO DE INICIAÇÃO CIENTÍFICA, 18., e ENCONTRO DE PÓS-GRADUAÇÃO, 11., 2009, Pelotas. Anais... Pelotas, 2009.

STRIEDER, M. L. Resposta do milho à redução do espaçamento entre linhas em diferentes sistemas de manejo. 2006. 94 f. Dissertação (Mestrado em Fitotecnia) - Universidade Federal do Rio Grande do Sul, Porto Alegre.

TREZZI, M. M. et al. Manejo químico de plantas daninhas na cultura do milho em função de características morfofisiológicas e redução de espaçamento da cultura. Planta Daninha, v. 26, n. 04 , p. 845-853, 2008.

VAZQUEZ, G. H.; SILVA, M. R. R. Influência do espaçamento entre linhas de semeadura em híbrido simples de milho. In: CONGRESSO NACIONAL DE MILHO E SORGO, 24., 2002, Florianópolis. Resumos... Florianópolis: ABMS, 2002. 